\title{
Assessing Coordination Performance Based on Centrality in an E-mail Communication Network
}

\author{
Sevgi Zeynep Dogan ${ }^{1}$; David Arditi, M.ASCE${ }^{2}$; Suat Gunhan, M.ASCE${ }^{3}$; and Bengi Erbasaranoglu ${ }^{4}$
}

\begin{abstract}
Building design and construction require the collective effort of diverse project participants. The coordination performance of these project participants is important for effective management and needs to be assessed periodically. However, there is no uncomplicated quantitative way to measure coordination. Measuring coordination is cumbersome and time-consuming particularly during the project execution phase. This study proposes an easy procedure for monitoring the coordinative performance of project participants. The degree, betweenness, and closeness centrality measures of the project participants in a wayfinding signage project at a major airport construction project are calculated using social network analysis on the e-mail communication network between the participants. A centrality index is defined for each firm based on the average of these three centrality measures. The firm's coordination score is also calculated based on content analysis of the sent and received e-mails between the participants. The coordination scores are found to be highly correlated with the centrality indices. To define the coordinative role of a firm, its centrality index could therefore be measured easily using a simple software and only the number and direction of e-mails exchanged between the participants rather than performing cumbersome and time-consuming content analysis of exchanges to calculate coordination scores. DOI: 10.1061/(ASCE)ME.1943-5479.0000255. @ 2014 American Society of Civil Engineers.
\end{abstract}

Author keywords: Coordination; Network centrality; E-mail communication.

\section{Introduction}

The construction project organization is a network of firms focused on achieving the goals of the project (Pryke and Pearson 2006). These firms act in a temporary organization whose articles of association are both contractual conditions and information exchange between the different participants (Winch 1989; Pryke 2004). This organization is temporary because it disbands after the project is completed. The firms are interdependent as they are embedded in a complex and dynamic network organization; and thus, each firm is influenced by other firms with which it must transact (Loosemore 1998; Pryke and Pearson 2006).

Good coordination among the firms involved in a construction project is vital for smooth project execution (Cheng et al. 2003). The coordination process among the interfirm project organization relies heavily on the structure of the communication network (Cheng et al. 2003). Information exchange is critical in the coordinative activity of project participants (Hossain et al. 2006; Hossain 2009). Project success has been found to be very sensitive to the effectiveness of information links in the network (Loosemore 1998). Research focusing on relational analysis in

\footnotetext{
${ }^{1}$ Assistant Professor, Dept. of Architecture, Izmir Institute of Technology, Urla, Izmir 35430, Turkey. E-mail: sevgidogan@iyte.edu.tr

${ }^{2}$ Professor, Dept. of Civil, Architectural and Environmental Engineering, Illinois Institute of Technology, Chicago, IL 60616 (corresponding author). E-mail: arditi@iit.edu

${ }^{3}$ Assistant Professor, Dept. of Construction Science, Univ. of Texas at San Antonio, San Antonio, TX 78207. E-mail: suat.gunhan@utsa.edu

${ }^{4}$ Design Professional, Ik Akademi Insaat Proje ve Taahhut A.S., Turan Gunes Bulvari, 651 Sokak, No. 4, Cankaya/Ankara 06550, Turkey; formerly, Graduate Student, Dept. of Architecture, Izmir Institute of Technology, Urla, Izmir 35430, Turkey. E-mail: bengi.erbasaranoglu@ikakademi.com.tr

Note. This manuscript was submitted on September 3, 2012; approved on September 4, 2013; published online on September 6, 2013. Discussion period open until September 25, 2014; separate discussions must be submitted for individual papers. This paper is part of the Journal of Management in Engineering, (C) ASCE, ISSN 0742-597X/04014047(8)/\$25.00.
}

construction management has recently utilized social network analysis for identifying the structural properties of various relations (Loosemore 1998; Pryke 2004, 2005; Pryke and Pearson 2006; Chinowsky et al. 2008, 2010a, b; Hossain 2009; Park et al. 2011). A good example is the work of Chinowsky et al. (2010b), which assesses project effectives by identifying project network misalignments. This study is based on the premise that an organization is structurally aligned when structures such as communication networks support the business strategy (Chan and Reich 2007). Social network analysis also facilitates the comparison of project participants' actions constrained and shaped by contractual links and communication channels.

The social network characteristic of centrality has the potential of identifying project participants in coordinator roles. The organizational structure displayed by contractual links affects and in turn is affected by the centrality of the role of a firm in the information exchange network. Network centrality measures are position indicators that describe the intensity of power and the prominence and influence of an actor in the network. Contractual links traditionally define the coordinator role of project participants. However, recent findings argue that a central position in the communication network of a project organization may also be an indication of a party's coordinator role (Hossain et al. 2006; Hossain 2009). The correlation between network centrality and coordination is widely discussed in social studies (Bavelas 1950; Leavitt 1951; Freeman et al. 1979). However, the construction domain lacks such discussion apart from the work of Hossain et al. (2006) and Hossain (2009). Although research indicates that the successful completion of a construction project depends heavily on effective coordination, adequate empirical research is still lacking on the association between the effectiveness of coordination and network centrality in interfirm organizational structures. Network centrality is evaluated in terms of both contractual network and communication network in this study.

This study highlights the interplay between coordinative activity and network centrality. It observes the correspondence of coordination scores and network centrality measures of project 
participants. The effects of network centrality on coordination are explored among the firms engaged in a particular project. The alignment of the patterns of contractual links and information exchange is investigated.

\section{Coordination in Construction}

Building design and construction represent the collective effort of diverse project participants. The participants are usually geographically separated when making interdependent decisions. This requires a great deal of coordination to maintain compatibility. Coordination refers to specific protocols and procedures in conjunction with the smooth flow of communication in all directions to achieve project objectives (Chitkara 1998). Technical interdependency and organizational independency in construction projects demand an effective coordination process that facilitates information flow and thus achieves high performance (Mokhtar et al. 1998; de Saram and Ahmed 2001; Chan et al. 2004).

Several coordination studies have been conducted in the design and construction domain. De Saram and Ahmed (2001) investigate the effectiveness of coordination in construction. Their findings indicate that identifying strategic activities, potential delays, and ensuring the timeliness of all work are the most important; conducting regular meetings, project reviews, and analyzing the project performance are the most time-consuming construction coordination activities. Cheng et al. (2003) propose a quantitative model for the evaluation of a project's communication efficiency under different organizational structures which could promote project coordination. Mokhtar et al. (1998) present an information model that facilitates the coordination of design information in the design change management process. Hossain (2009) investigates the effect of organizational network centrality on coordination effectiveness in a construction project.

Coordination is an abstract concept and is difficult to measure. Coordination is typically assessed using qualitative methods, i.e., by identifying those participants who display dominant roles. Malone and Crowston (1994) define coordination as managing dependencies between participants. They argue that there are fundamental coordination processes that occur in all coordinated systems. Measuring coordination is to measure the effectiveness of the following key coordination processes excerpted from the work of Malone and Crowston (1994).

\section{Managing Shared Resources}

Whenever multiple activities share limited resources (e.g., money, storage space, or an actor's time), a resource allocation process is needed to manage the interdependencies among these activities. An actor's ability to effectively coordinate scarce resources and to maximize the impact of these resources is a major part of the coordination process that can be measured.

\section{Managing Simultaneity Constraints}

Some of the multiple activities in a project may need to occur at the same time (or cannot occur at the same time). This coordination process deals with these kinds of dependencies among activities that need to be synchronized. An actor's ability to effectively manage simultaneity constraints can be measured.

\section{Managing Producer/Consumer Relationships}

The situation where one activity produces something that is used by another activity occurs in all physical manufacturing processes.
For instance, in bridge construction, the piers need to be erected before the deck can be placed. Producer/consumer relationships often lead to prerequisite constraints. A very common dependency between a producer activity and a consumer activity is that the producer activity must be completed before the consumer activity can begin (finish-to-start relationship). Other dependencies may involve start-to-start, start-to-finish, and finish-to-finish relationships. Managing dependencies requires not only scheduling these activities but also monitoring that producer activities have been completed before their results are needed. The critical-path method (CPM) is often used to help schedule construction projects with multiple activities and complex prerequisite structures. An actor's ability to manage producer/consumer information between the members of the network is an important coordination process that can be measured.

\section{Managing Task/Subtask Dependencies}

Activities are sometimes split into a number of subactivities to introduce greater detail to the planning/execution processes. These subactivities need to be coordinated effectively if one wants to achieve the objectives represented by the main activities. An actor's ability to decompose activities into subactivities to achieve a higher level goal is part of the coordination process and it can be measured.

\section{Network Centrality}

Social network analysis is a methodology used to identify the interactions in social structures. Graphs or sociograms are created with nodes representing the parties in a network and links between the nodes representing the relations between the parties. Social network analysis emphasizes the relational measures among the parties represented in a graph or sociogram. The concept was introduced by Moreno (1960) and has recently been utilized in the engineering and construction field (Loosemore 1998; Pryke 2004, 2005; Pryke and Pearson 2006; Chinowsky 2008, 2010a, b; Hossain 2009; Park et al. 2011).

Social network analysis approach appeals to researchers in the construction domain because of its investigative capability of the various relationships among project participants and project organizations. It is primarily focused on issues of information exchange (Loosemore 1998), project governance (Pryke and Pearson 2006), coalitions (Pryke 2004), procurement (Pryke 2005), knowledge sharing to achieve high performance (Chinowsky et al. 2008, 2010a), and collaboration strategies for overseas construction projects (Park et al. 2011). Furthermore, hybrid approaches suggest connecting social network analysis with building information modeling (Taylor and Bernstein 2009).

Centrality measures the distribution of relationships through a network. It describes the influence of a node based on how well connected the node is in the network. Previous empirical studies provide nodes that exhibit high centrality and thus achieve high levels of performance (Wasserman and Faust 1997; Ahuja et al. 2003; Pryke 2004; Tallberg 2004; Schilling and Phelps 2007).

Experiments that demonstrated a link between network centrality and coordination of small groups were conducted by Bavelas (1950), Leavitt (1951), and Freeman et al. (1979). The results indicated that central network positions are most conducive to coordination and that central nodes are most often identified as the coordinator of the group. There has been a proliferation of research on network centrality and Freeman (1978) markedly differentiated among degree centrality, betweenness centrality, and closeness centrality. Three centrality measures of Freeman (1978) are interpreted for communicative positions of construction firms in a project network. 


\section{Degree Centrality}

Degree centrality measures the extent to which a firm is connected to the firms adjacent to it (Freeman 1978). A firm's in-degree and out-degree centralities represent the degree to which the firm is a receiver or sender of information from or to the firm's neighbors, respectively. A firm's in-degree centrality is an indication of the firm's accessibility to information (Wasserman and Faust 1997). A firm's out-degree centrality is an indication of the firm's control over a network and of the dependence of the network upon the firm (Wasserman and Faust 1997).

\section{Betweenness Centrality}

Betweenness centrality measures the extent to which a firm plays the part of a coordinator of different firms' activities by controlling the information flowing between them (Freeman 1978). These firms occupy a critical position in the network in that they keep the network together (Wasserman and Faust 1997). Weaknesses at these critical points can harm the network (Loosemore 1998).

\section{Closeness Centrality}

Closeness centrality measures the distances of a firm to every other firm in the network (Freeman 1978). Distance is defined as the number of intermediaries, which two firms have to go through to communicate (Freeman 1978). Closeness centrality reflects the extent to which the network is concentrated around one firm. A firm's closeness centrality is a reflection of its dependence/ independence (Wasserman and Faust 1997). A firm that is close to many other firms finds it difficult to act independently without the others knowing (Wasserman and Faust 1997).

\section{Project Description}

The case study involves the Istanbul Sabiha Gokcen International Airport (ISGIA) wayfinding signage project. ISGIA is a major airport located on the Asian part of Istanbul. Its new terminal building serves 10 million passengers annually. ISGIA was undertaken by using build-operate-transfer (BOT), a common project delivery system used in airport projects in Turkey. The owner of the project was Airport Management and Aviation, a government agency associated with the Turkish Department of Defense. The other party in the BOT arrangement was the three-party consortium, LimakGrandhi Mallikarjuna Rao (GMR)-Malaysia Airports Holdings Berhad (MAHB), who signed the BOT contract for an amount of 1.932 billion Euros. The consortium awarded the architectural design project via the competition among four invited design firms to the Tekeli-Sisa Architectural Partnership and the construction contract to the joint venture Limak-GMR. The contract amount for construction was 330,857,195 Euros.

The wayfinding signage design project of this new terminal building's interiors and exteriors is used as a case study in this paper. The joint venture Limak-GMR subcontracted the wayfinding signage design/build project to a firm called Yonsis, who used a firm called Woodhead as a consultant to perform the schematic design, developing signs, specifying materials, fabrication details, and font styles and colors. Yonsis also engaged a firm called RGB as a management consultant. RGB did not have any responsibility for signage programming but coordinated the activities of the participants of the wayfinding project by providing consulting services such as scheduling work, organizing meetings, monitoring requests for information, submittals and change orders, and overseeing project closeout. The project participants only came together twice physically throughout the project; hence, RGB administered the project via teleconference meetings and e-mail communication. Fig. 1 shows the organizational schema.

\section{Methodology of the Study}

A communication network may involve using face-to-face meetings, sending letters and memos, issuing newsletters, posting announcements on websites, making telephone calls, organizing teleconferences, encouraging chat room discussions, and sending/ receiving text messages and e-mails. Corporations routinely use a combination of these tools for the purpose of coordinating complex, distributed work. However, the study was performed using

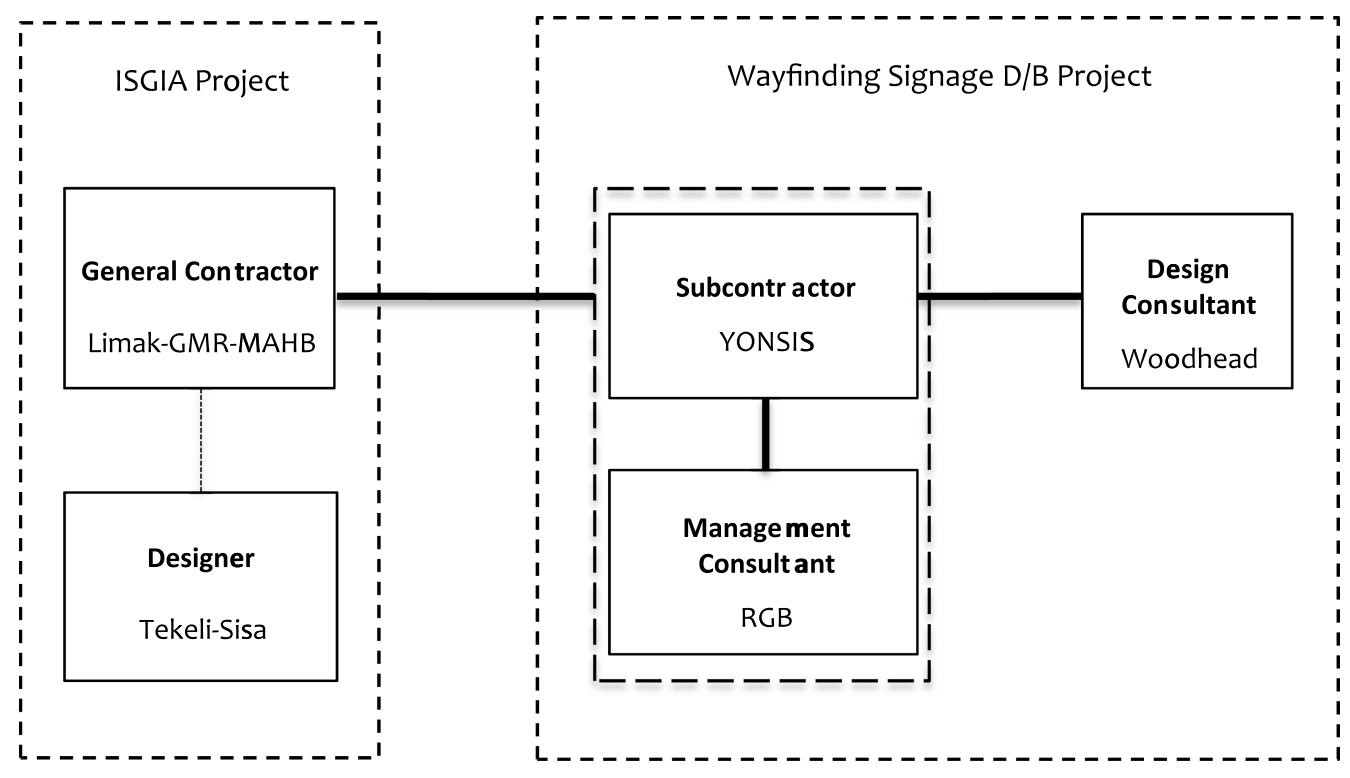

Note: The links between the boxes represent contractual agreements

Fig. 1. Contractual network 
only the e-mail communication between the parties involved in the wayfinding signage design project. The reason for using the e-mail communication data set was the geographic separation of the parties because e-mail was economical and frequently used in organizations that coordinate activities across geographic distance. The construction site was located in Istanbul. The three-party consortium Limak-GMR-MAHB that signed the contract was an international joint venture (Limak-Turkey, GMR-India, MAHBMalaysia), and the designer Tekeli-Sisa and the consulting firm RGB were local project participants. The subcontractor Yonsis that was in charge of the wayfinding signage design project was located in Izmir, Turkey and the sub-subcontractor Woodhead was located in Adelaide, Australia. E-mail traffic took place over a period of 6 months. The complete e-mail communication data of 216 sent and received e-mails were reviewed by Erbasaranoglu (2011). The use of this intense e-mail communication to measure network relations and coordination patterns is justified in this study because project participants physically only got together twice in 6 months, and communication via phone or any other method was rare if ever used.

The methodology of the study involves three parts: (1) activating the coordination processes of Malone and Crowston (1994) for the e-mail data set obtained from the wayfinding signage design project and calculating coordination scores for the project participants; (2) conducting social network analysis for the same data set and calculating network centrality measures and defining centrality indices for project participants; and (3) evaluating correlation between coordination performance and network centrality of project participants.

\section{Part 1: Measuring Coordination}

Malone and Crowston (1994) define coordination as managing the dependencies between activities. Although coordination is abstract and difficult to quantify, Hossain et al. (2006) and Hossain (2009) measured coordination based on the effectiveness of the key coordination processes defined by Malone and Crowston (1994). As discussed in the previous section, Malone and Crowston (1994) characterize four different kinds of dependencies and identify the coordination processes that can be used to manage them, namely, (1) the firm's ability to effectively coordinate scarce resources and to maximize their impact, (2) the firm's ability to manage the producer/consumer relationships via transfer of information between the other firms in the network, (3) the firm's ability to manage simultaneity constraints setting up task synchronization between firms, and (4) the firm's ability to manage tasks/subtasks effectively for achieving higher-level objectives. Activating the coordination processes of Malone and Crowston (1994) involves highlighting the coordination processes identified by Malone and Crowston (1994) for managing resource dependencies (second column in Table 1), identifying the coordination processes in the context of the wayfinding signage design project (third column in Table 1), and developing key phrases that could capture those

Table 1. Procedure for Activating Coordination Theory

\begin{tabular}{|c|c|c|c|c|}
\hline \multirow[b]{2}{*}{ Dependency } & \multicolumn{2}{|c|}{ Coordination processes for managing resource dependency } & \multirow{2}{*}{$\begin{array}{l}\text { Examples of } \\
\text { coordinative } \\
\text { key phrases }\end{array}$} & \multirow[b]{2}{*}{ Weight } \\
\hline & $\begin{array}{l}\text { Generic processes (Malone and } \\
\text { Crowston 1994) }\end{array}$ & $\begin{array}{l}\text { Specific processes for wayfinding } \\
\text { signage project }\end{array}$ & & \\
\hline \multirow[t]{8}{*}{ Shared resources } & - Priority order & - Ordering tasks & Please send & 4.95 \\
\hline & - Budgeting processes & - Directing processes & Please make sure & 2.32 \\
\hline & - Managerial decision & - Asking to complete a task & Please submit & 2.00 \\
\hline & - Organizational power & & Please get & 2.00 \\
\hline & - Resource dependence & & Please upload & 1.58 \\
\hline & & & Please prepare & 1.00 \\
\hline & & & Please change & 1.00 \\
\hline & & & Please organize & 1.00 \\
\hline \multirow[t]{8}{*}{ Simultaneity constraints } & - Scheduling & - Organizing tasks & Arrange & 4.75 \\
\hline & - Synchronization & - Marking milestones & Due (date) & 4.32 \\
\hline & - Meeting scheduling & - Assigning durations & Meeting call & 3.00 \\
\hline & - Certain kinds of process modeling & - Communicating the time of an event & Make a schedule & 2.58 \\
\hline & & & Submission date & 0.30 \\
\hline & & & Given time & 0.30 \\
\hline & & & Required time & 0.30 \\
\hline & & & Extra time & 0.30 \\
\hline \multirow{9}{*}{$\begin{array}{l}\text { Producer/consumer } \\
\text { relationships }\end{array}$} & - Participatory design & - Ask for information & I sent & 6.55 \\
\hline & - Market research & - Pass information & Attached is & 5.95 \\
\hline & $\begin{array}{l}\text { - Inventory management } \\
\text { - (Just in time) }\end{array}$ & - Balancing simultaneous efforts & I uploaded & 4.95 \\
\hline & - Standardization & - Correspondence & ASAP & 3.46 \\
\hline & - Concurrent engineering & & For your information & 3.00 \\
\hline & & & I provide & 2.80 \\
\hline & & & I updated & 2.00 \\
\hline & & & Please download & 1.58 \\
\hline & & & The file is available & 1.00 \\
\hline \multirow[t]{8}{*}{ Tasks/subtasks } & - Strategic planning & - Planning tasks & I recommend & 3.70 \\
\hline & - Management by objectives & - Deciding on a task objective & I need to & 3.58 \\
\hline & & & I think & 3.46 \\
\hline & - Methods of grouping people into units & - Organizing a work package & I can add & 3.00 \\
\hline & & & In order to finish & 2.80 \\
\hline & - Goal selection & - Challenging higher-level objectives & For changing & 2.58 \\
\hline & - Task decomposition & & We can redesign & 2.32 \\
\hline & & & We should revise & 2.23 \\
\hline
\end{tabular}


processes in e-mails (fourth column in Table 1). Key phrase identification is specific to the context and was done by a subjective review in this study. Pentland (1995) states that it is difficult to imagine a coordination-related constraint that does not vary with context. Accordingly, there is no universal grammar for organizational processes, and this study used a context-specific categorization for key phrase identification.

Following the same method used in the study of Hossain (2009), the number of times a specific key phrase was used in coordinative sentences that are part of the e-mail messages between the project participants was counted to determine frequency. The base two logarithm of the determined frequency was assigned to be the weight of that phrase (last column in Table 1). Base two logarithms are used to prevent fluctuations and create a normal distribution. The weights of key phrases ranged between 0.30 and 6.55. The weighted coordination score of each project participant was calculated by the sum-product of the phrase frequency and its assigned weight. For example, for the key phrase please upload, the number of times this phrase is mentioned in the e-mails is counted; this number is converted to base two logarithm and its weight is determined. The number of times an actor has used the phrase please upload is counted; this number is multiplied by the weight calculated in the preceding step, and the coordination score is calculated for this actor relative to this phrase. The sum of all coordination scores for all the phrases used by this actor yields this actor's overall coordination score. Fig. 2 shows the coordination scores for all participants in the wayfinding signage design project.

\section{Part 2: Measuring Network Centrality}

Centrality measurements depend on social network analysis, a methodology used to identify the relational conditions of social structures by examining the interactions and the interrelationships among a set of actors. A relational structure can be recognized in communication flows such as electronic mailing. UCINET, a software developed by Borgatti et al. (2002) for relatively small networks (Loosemore 1998), was used to analyze the data extracted from e-mail communications between the participants of the wayfinding signage design project. It produced an information exchange network as seen in Fig. 2. The software differentiates between sent and received e-mails. The number of sent and received e-mails by each project participant was added up provided that the e-mail was sent directly to the recipient [no carbon copy (CC) or blind carbon copy (BCC)]. The rationale for ignoring the e-mails received as $\mathrm{CC}$ and $\mathrm{BCC}$ is that the study of social networks requires considering not only the frequency but also the reciprocity of such social interactions; $\mathrm{CC}$ and $\mathrm{BCC}$ e-mails are usually intended as passive information propagation, rather than establishing a two-way relationship (Klimt and Yang 2004).

The frequency of the scored e-mails is reflected in weighted arrows and the numbers next to each arrow in Fig. 2. As discussed earlier, network centrality is an indicator of the power and influence of a firm; it represents how strategically a firm is connected in the network. Based on the definitions of Freeman (1978), degree centrality denotes the number of nodes connected to one node in particular; betweenness centrality is the extent to which a firm lies between other pairs of firms (it is the proportion of all the shortest paths (i.e., geodesic distances) between pairs of other firms that pass through the firm); closeness centrality is based on the sum of the geodesic distances from each node to all other nodes. For a directed information network, degree and closeness centrality are classified as in-degree, in-closeness, out-degree, and out-closeness depending on the direction of the relationship. The following equations [Eqs. (1)-(3)] show the mathematical forms of degree, betweenness, and closeness centrality, respectively (de Nooy et al. 2005):

$$
\text { Degree centrality }=\frac{\sum_{j=1}^{n}\left(Z_{i j}+Z_{j i}\right)}{\sum_{i=1}^{n} \sum_{j=1}^{n}\left(Z_{i j}\right)}
$$

where $Z_{i j}=$ number of links that a node $i$ receives from a node $j$; and $n=$ number of existent nodes

$$
\text { Betweenness centrality }(\text { of node } i)=\sum_{s, t: s \neq t \neq i} \frac{\sigma_{i}(s, t)}{\sigma(s, t)}
$$

where $\sigma_{i}(s, t)=$ number of shortest paths from node $s$ to node $t$ that pass through node $i ; \sigma(s, t)=$ total number of shortest paths from node $s$ to node $t$

$$
\text { Closeness centrality }(\text { of node } i)=\frac{n-1}{\sum_{k \in N} d(i, k)}
$$

where $n=$ number of nodes; $N=$ total number of nodes; $k=k$ th node in the network; and $d(i, k)=$ length of the shortest path between nodes $i$ and $k$.

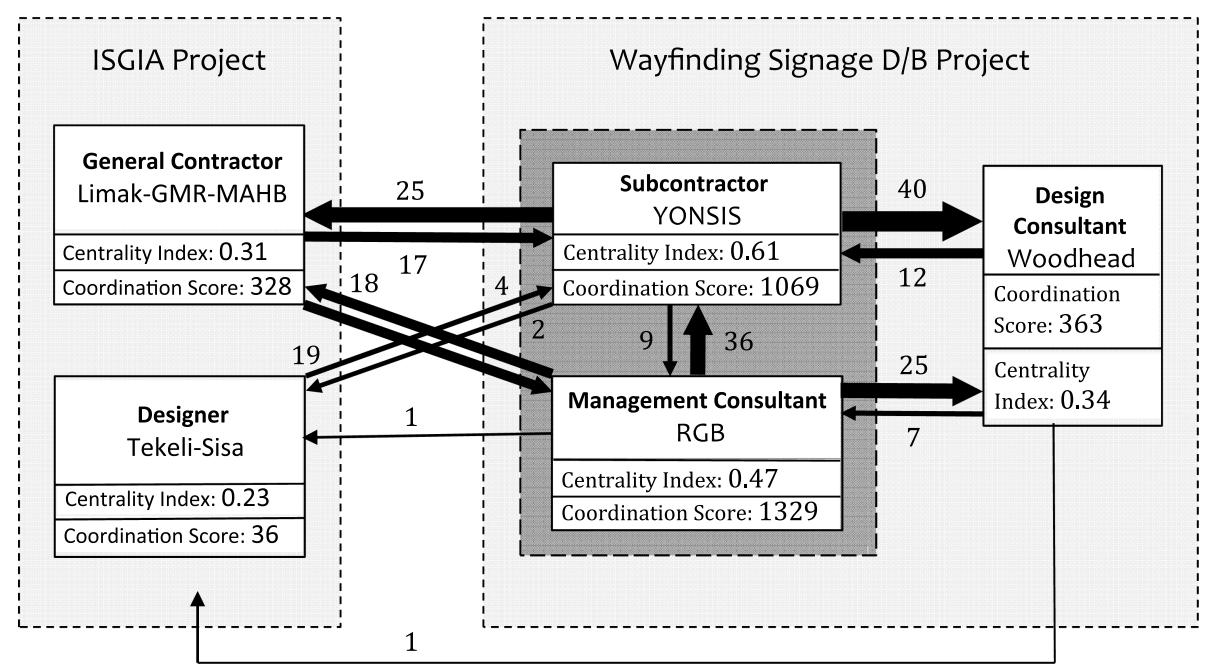

Note: Number next to arrows represent the number of emails

Fig. 2. E-mail communication network 
UCINET (Borgatti et al. 2002) provided centrality calculations based on the e-mail data set used in the study. The results are presented in Table 2 . The centrality values were normalized so that they are independent of the size of the network and range between 0 and 1 . The average of the three centrality measures in Table 2 represents the centrality index of each firm.

\section{Part 3: Evaluating the Correlation between Coordination Performance and Network Centrality}

The correlation between the coordination scores and the centrality indices was investigated by using Spearman rank correlation (Table 3). The Spearman rank order correlation coefficient $(\rho)$ is a nonparametric measure of the strength and direction of association that exists between two variables measured on an ordinal scale (Hollander and Wolfe 1999). In applications where ties are known to be absent, such as this case, the Spearman correlation coefficient can be calculated by using the relationship presented in Eq. (4)

$$
\rho=\frac{6 \sum\left(x_{i}-y_{i}\right)^{2}}{n\left(n^{2}-1\right)}
$$

where $x_{i}-y_{i}$ represents the differences between the ranks of the variables; and $n$ is the number of variables. This coefficient takes values between -1 and +1 , where zero represents no correlation.

\section{Findings and Discussion}

The findings of the study are discussed firstly by the positions of the firms in terms of centrality in the e-mail communication network, and then their network positions are compared to their coordination performance.

\section{Network Centrality}

The subcontractor Yonsis has the highest centrality index, with the highest degree, betweenness, and closeness centrality measures (Table 2). The high centrality index of the subcontractor Yonsis agrees with its responsibilities defined in its contracts with the general contractor and two consultants. These contractual links (Fig. 1) justify the subcontractor's communication links in the information exchange network (Fig. 2).

High-degree centrality indicates high activity and involvement in the network (Wasserman and Faust 1997). According to Fig. 2, the subcontractor Yonsis is connected to all the firms in the information exchange network and is the sender and recipient of a large number of e-mails to and from these firms. Wasserman and Faust (1997) argue that having many links represents being influential and respectable.

Table 2. Normalized Centrality Measures and Centrality Index

\begin{tabular}{|c|c|c|c|c|}
\hline \multirow{2}{*}{$\begin{array}{l}\text { Wayfinding signage } \mathrm{D} / \mathrm{B} \\
\text { project participant firms }\end{array}$} & \multicolumn{3}{|c|}{ Normalized centrality measures } & \multirow{2}{*}{$\begin{array}{l}\text { Centrality } \\
\text { index }\end{array}$} \\
\hline & Degree & Betweenness & Closeness & \\
\hline Subcontractor (Yonsis) & 0.45 & 0.38 & 1.00 & 0.61 \\
\hline $\begin{array}{l}\text { Management consultant } \\
\text { (RGB) }\end{array}$ & 0.36 & 0.13 & 0.90 & 0.47 \\
\hline $\begin{array}{l}\text { Design consultant } \\
\text { (Woodhead) }\end{array}$ & 0.27 & 0.00 & 0.74 & 0.34 \\
\hline $\begin{array}{l}\text { General contractor } \\
\text { (Limak-GMR-MAHB) }\end{array}$ & 0.25 & 0.00 & 0.67 & 0.31 \\
\hline Designer (Tekeli-Sisa) & 0.03 & 0.00 & 0.69 & 0.23 \\
\hline
\end{tabular}

Betweenness centrality depends on the e-mail interactions between two nonadjacent firms. The firms lying in between might potentially have some control over the interactions between the two nonadjacent firms (Wasserman and Faust 1997). The subcontractor Yonsis has the most central position in betweenness measurements (Table 2). Because of its position, it is able to control the communication flow easily. According to Hossain (2009), a higher betweenness score may indicate a leadership position in the network and may encourage a firm to contribute more to solutions in response to the problems encountered in the project. According to the information in Fig. 2, Yonsis is a controller and a leader in the network.

Closeness centrality focuses on how close a firm is to all the other firms in the network. Firms with high closeness centrality can be very active in communicating information to the other firms (Wasserman and Faust 1997). The subcontractor Yonsis obtained the highest closeness centrality score (Table 2), which indicates that the subcontractor need not rely on other firms for the relaying of information (Wasserman and Faust 1997). According to Wasserman and Faust (1997), the closeness view of centrality depends on economic considerations; thus, in problem solving relying on communication links, efficient solutions occur when one firm has the shortest communication paths to the other firms. This implies that communicating with the subcontractor Yonsis can be accomplished in a direct, efficient, easy, and economic manner.

The management consultant RGB of the subcontractor Yonsis has the second highest centrality index, with the second highest degree, betweenness, and closeness centrality measures (Table 2). The management consultant RGB is contractually linked to the subcontractor Yonsis with management responsibilities that includes the smooth execution of the wayfinding signage design/ build project. Thus, it acts in harmony with the central firm Yonsis, presenting a cocentral position in the e-mail communication network. The cocentral position is indicated by the dense communication links it holds (Fig. 2).

The design consultant Woodhead is contractually linked to the subcontractor Yonsis with the design responsibilities. It holds less communication links than the management consultant RGB, holding the third place for centrality after it (Table 2). The difference in consultancy requirements justifies the difference in the involvement of these firms in the e-mail communication network.

The three-party consortium Limak-GMR-MAHB and the designer Tekeli-Sisa have the fourth and the fifth rankings in the centrality measures and centrality indices (Table 2), which indicates that they have peripheral positions in the e-mail communication network (Fig. 2). They are the main firms in the major airport project, whereas they stand on the periphery for the airport's wayfinding signage design project.

\section{Coordination versus Network Centrality}

The coordination scores of the firms involved in the wayfinding and signage design project are presented in Fig. 2. The subcontractor Yonsis and its management consultant RGB conduct the highest coordinative activity. Coordination is defined and measured as managing dependencies. It is obvious and contractually appropriate that the subcontractor of the design build project and its management consultant are the main firms in charge of managing dependencies. Other firms show far less coordinative activity than these two leading firms.

The coordination scores and the centrality indices presented in Fig. 2 were compared to see if a correlation exists between them. The findings show that coordination scores are highly correlated with centrality indices with a Spearman rank correlation coefficient 
Table 3. Spearman Rank Correlation between Coordination Scores and Centrality Indices

\begin{tabular}{lcc}
\hline $\begin{array}{l}\text { Wayfinding signage D/B project } \\
\text { participant firms }\end{array}$ & $\begin{array}{c}\text { Coordination } \\
\text { score }\end{array}$ & $\begin{array}{c}\text { Centrality } \\
\text { index }\end{array}$ \\
\hline Subcontractor (Yonsis) & 1,069 & 0.61 \\
Management consultant (RGB) & 1,329 & 0.47 \\
Design consultant (Woodhead) & 363 & 0.34 \\
General contractor (Limak-GMR-MAHB) & 328 & 0.31 \\
Designer (Tekeli-Sisa) & 36 & 0.23 \\
Spearman rank correlation coefficient & \multicolumn{2}{c}{$\rho=0.90$} \\
\hline
\end{tabular}

( $\rho$ ) of 0.90 (Table 3). The results support previous findings that network centrality has an effect on coordination (Bavelas 1950; Leavitt 1951; Freeman et al. 1979; Hossain et al. 2006; Hossain 2009).

Coordination scores were also checked for correlations against measures for each centrality type. The findings show that coordination scores are also highly correlated with centrality measures of degree, betweenness, and closeness with Spearman rank correlation coefficients $(\rho)$ of $0.90,0.80,0.80$, respectively. Overall, it can be concluded that the correlations between coordination scores and centrality types are uniformly high.

\section{Conclusion}

Five multinational firms participated in the design/build project of wayfinding signage in a major airport construction in Istanbul. The electronic information exchange between the firms was analyzed to assess the firms' coordination performance and their centrality in the project network. The association between network centrality and coordination performance was investigated. The centrality indices were obtained by using a social network analysis software called UCINET (Borgatti et al. 2002), and coordination scores were calculated according to the methodology of Hossain (2009).

The empirical evidence shows that coordination scores are highly correlated with centrality indices (Table 3 ). The findings also imply that agreements a firm hold in the contractual network (Fig. 1) relate to the communication links it builds in the e-mail communication network (Fig. 2) which then relates to its centrality index (Table 2). In a construction project (Fig. 1), the firm that receives a contract to perform a project is also expected to perform the coordination function. Measuring coordination through a cumbersome and time-consuming e-mail content analysis to reveal coordinative communication is difficult. Thus, this study suggests an easy procedure of measuring centrality to check if the coordinator role implied by the contractual links is actually in effect or not. Measuring centrality using a social network analysis software is easy and fast once an adjacency matrix is constructed and the sent and received e-mail numbers of the firms are entered. Thus, during the execution of the project, the project manager could refer to the centrality index of a firm to check if the level of coordination required, given their contractual agreement, is being met. A higher centrality index for a firm would indicate that the firm has critical contractual obligations. If a firm designated for higher responsibility as defined by its contractual links shows a relatively lower centrality index, it should be monitored closely as it may indicate a deficiency in management and may lead to delays and cost overruns. Whether a correlation exits between centrality index and managerial performance relative to budget, duration, and quality needs to be researched in future work. Using the same methodology, further research could also investigate the degree to which shared resources, simultaneity constraints, owner/contractor relationships, and task/subtask dependencies are managed.

The study has implications relative to project delivery systems and project success. First off, project participants perform different coordinative activities in different project delivery systems. The centrality of a project participant can be anticipated based on the nature of the project delivery system and assessed using the proposed method. In the ISGIA project, Yonsis was expected to occupy a central position because it performed a design/build function. The dynamics of the coordination system would have been different had Yonsis been hired just to install signage. Secondly, there is evidence in the literature that effective coordination is conducive to project success (De Saram and Ahmed 2001; Hossain 2009; Jha and Misra 2007). Assessing the parties' communication performance and their centrality relative to organizational coordination efforts do affect project coordination, and by implication, project success.

\section{References}

Ahuja, M. K., Galletta, D. F., and Carley, K. M. (2003). "Individual centrality and performance in virtual R\&D groups: An empirical study." Manage. Sci., 49(1), 21-38.

Bavelas, A. (1950). "Communication patterns in task-oriented groups." J. Acoust. Soc. Am., 22(6), 271-282.

Borgatti, S. P., Everett, M. G., and Freeman, L. C. (2002). UCINET for windows: Software for social network analysis, Analytic Technologies, Harvard, MA.

Chan, A. P. C., Chan, D. W. M., Chiang, Y. H., Tang, B. S., Chan, E. H. W., and Ho, K. S. K. (2004). "Exploring critical success factors for partnering in construction projects." J. Constr. Eng. Manage., 10.1061/ (ASCE)0733-9364(2004)130:2(188), 188-198.

Chan, Y. E., and Reich, B. H. (2007). "IT alignment. What have we learned?" J. Inform. Technol., 22(4), 297-315.

Cheng, M. Y., Su, C. W., and You, H. Y. (2003). "Optimal project organizational structure for construction management." J. Constr. Eng. Manage., 10.1061/(ASCE)0733-9364(2003)129:1(70), 70-79.

Chinowsky, P., Diekmann, J., and Galotti, V. (2008). "Social network model of construction." J. Constr. Eng. Manage., 10.1061/(ASCE) 0733-9364(2008)134:10(804), 804-812.

Chinowsky, P., Diekmann, J., and O'Brien, J. (2010a). "Project organizations as social networks." J. Constr. Eng. Manage., 10.1061/(ASCE) CO.1943-7862.0000161, 452-458.

Chinowsky, P., Taylor, J. E., and Di Marco, M. (2010b). "Project network interdependency alignment: New approach to assessing project effectiveness." J. Manage. Eng., 10.1061/(ASCE)ME.1943-5479 $.0000048,170-178$.

Chitkara, K. K. (1998). Construction project management: Planning, scheduling and controlling, Tata McGraw-Hill Publications, New Delhi, India.

De Nooy, W., Mrvar, A., and Batageli, V. (2005). Exploratory social network analysis with Pajek, Cambridge University Press, Cambridge, U.K.

De Saram, D. D., and Ahmed, S. M. (2001). "Construction coordination activities: What is important and what consumes time." J. Manage. Eng., 10.1061/(ASCE)0742-597X(2001)17:4(202), 202-212.

Erbasaranoglu, B. (2011). "Analyzing the communication and coordination processes in Sabiha Gokcen International Airport's new terminal building wayfinding project." Master thesis, Izmir Institute of Technology, Izmir, Turkey.

Freeman, L. C. (1978). "Centrality in social networks: Conceptual clarification." Soc. Networks, 1(3), 215-239.

Freeman, L. C., Roeder, D., and Mulholland, R. R. (1979). "Centrality in social networks: II. Experimental results." Soc. Networks, 2(2), $119-141$.

Hollander, M., and Wolfe, D. (1999). Nonparametric statistical methods, 2nd Ed., Wiley-Interscience, Hoboken, NJ. 
Hossain, L. (2009). "Communications and coordination in construction projects." Constr. Manage. Econ., 27(1), 25-39.

Hossain, L., Wu, A., and Chung, K. K. S. (2006). "Actor centrality correlates to project based coordination." Proc., 2006 20th Anniversary Conf. on CSCW'06 Computer Supported Cooperative Work, ACM, New York, NY, 363-372.

Jha, K. N., and Misra, S. (2007). "Ranking and classification of construction activities in Indian project." Constr. Manage. Econ., 25(4), 409-421.

Klimt, B., and Yang, Y. (2004). "The Enron corpus: A new dataset for email classification research." Proc., 2004 15th European Conf. on Machine Learning, Springer, Berlin/Heidelberg, Germany, 217-228.

Leavitt, H. J. (1951). "Some effects of certain communication patterns on group performance." J. Abnorm. Soc. Psychol., 46(1), 38-50.

Loosemore, M. (1998). "Social network analysis: Using a quantitative tool within an interpretative context to explore the management of construction crises." Eng. Construct. Architect. Manage., 5(4), 315-326.

Malone, T. W., and Crowston, K. (1994). "The interdisciplinary study of coordination." ACM Comput. Surv., 26(1), 87-119.

Mokhtar, A., Bedard, C., and Fazio, P. (1998) "Information model for managing design changes in a collaborative environment." J. Comput. Civ. Eng., 10.1061/(ASCE)0887-3801(1998)12:2(82), 82-92.

Moreno, J. L. (1960). The sociometry reader, Free Press, Glencoe, IL.

Park, H., Han, S. H., Rojas, E. M., Son, J. W., and Jung, W. (2011). "Social network analysis of collaborative ventures for overseas construction projects." J. Constr. Eng. Manage., 10.1061/(ASCE)CO.1943-7862 .0000301, 344-355.

Pentland, B. T. (1995). "Grammatical models of organizational processes." Organ. Sci., 6(5), 541-556.

Pryke, S., and Pearson, S. (2006). "Project governance: Case studies on financial incentives." Build. Res. Inf., 34(6), 534-545.

Pryke, S. D. (2004). "Analysing construction project coalitions: Exploring the application of social network analysis." Constr. Manage. Econ., 22(8), 787-797.

Pryke, S. D. (2005). "Towards a social network theory of project governance." Constr. Manage. Econ., 23(9), 927-939.

Schilling, M. A., and Phelps, C. C. (2007). "Interfirm collaboration networks: The impact of large-scale network structure on firm innovation." Manage. Sci., 53(7), 1113-1126.

Tallberg, C. (2004). "Testing centralization in random graphs." Soc. Networks, 26(3), 205-219.

Taylor, J. E., and Bernstein, P. G. (2009). "Paradigm trajectories of building information modeling practice in project networks." J. Manage. Eng., 10.1061/(ASCE)0742-597X(2009)25:2(69), 69-76.

UCINET Software [Computer software]. Lexington, KY, Analytic Technologies.

Wasserman, S., and Faust, K. (1997). Social network analysis: Methods and applications, Cambridge University Press, Cambridge, U.K.

Winch, G. (1989). "The construction firm and the construction project: A transaction cost approach." Constr. Manage. Econ., 7(4), 331-345. 